\title{
The simulation in health care in orthopedics
}

\begin{abstract}
The changes in education, secondary to the demand for health care in the $21^{\text {st }}$ century, have exploited different strategies to improve the quality of training of health professionals, simulation in health care has had a boom in recent decades and the branch of Orthopedics has not been exempt. There are different approaches that can be reached with simulation in orthopedics, from simulation management and simulators or virtual reality programs to influence the learning curve and improve technical and non-technical skills, classify the level of those skills, assess and certify professional competencies, among others.

Most studies in orthopedics focus on surgical areas, leaving aside the approach of clinical and non-technical skills, as well as undergraduate, so one of the challenges of simulation within the area of orthopedics is to expand the vision towards these areas, since it has been demonstrated that at all levels, the simulation generates significant improvements in the training and performance of health personnel, generating a direct impact on patient safety.
\end{abstract}

Keywords: Simulation, orthopedics, teaching, learning, virtual reality, simulators, evaluation, arthroscopy
Volume II Issue I - 2019

\author{
Ana Gabriela Ortiz Sánchez, Hugo Erick \\ Olvera Cortés, Sara Morales López, Argimira \\ Vianey Barona Núñez \\ Facultad de Medicina, Universidad Nacional Autónoma de \\ México, México
}

Correspondence: Ana Gabriela Ortiz Sánchez, Instructor en Simulación de la Facultad de Medicina, Camino a santea Fe No. I231, Edificio $3^{\mathrm{a}}$ Depto 102, Colonia Cuevitas, Delegación Álvaro Obregón, Ciudad de México, México, Tel 5529098772; Emaildra.ortizs@gmail.com

Received: August 04, 2017 | Published: January 29, 2019

\section{Introduction}

One of the great challenges of medical education in the $21^{\text {st }}$ century, both in undergraduate and postgraduate studies, is the great demand that the population has for medical care in terms of both quantity and quality; however, the ethical dilemma of practices on the patient by a physician in training is an element that acts to the detriment of the patient's safety, generating a conflict in the application of the acquired knowledge on the part of the students when transforming them into skills .

Being able to practice in a safe environment before attending a patient that leads to a vital responsibility, is an advantage given by clinical simulation, which is defined by David Gaba as "a technique not a technology - to replace or amplify real experiences with guided experiences that evoke or replicate aspects of the real world in fully interactive manner ".

In the last decades, especially in the last 10 years simulation has begun to be used exponentially to improve technical and nontechnical skills of health professionals that impact on patient safety. In orthopedics, the use of simulation has been applied in different branches to reduce the procedural learning curve, to understand physiopathological processes, to evaluate skills, to maintain an environment of continuous training, certification, identification of novices and experts, among others.

\section{Discussion}

Simulation has been used in orthopedics to improve patient safety in different ways, one of them and the most common is the development of skills, these can be classified into clinical skills and surgical skills, where each has technical and non-technical components. One of the surgical skills whose teaching has been most influenced by the simulation (and there is a record) is arthroscopy, which requires surgical skills that can be acquired or significantly improved with the use of high-fidelity simulators ${ }^{2-6}$ or virtual reality, ${ }^{7-12}$ at repetitive intervals and with deliberate practice, to ensure a continuous training process and to maintain the skills of the physician; however the use of these simulators requires a great monetary investment due to the high cost of acquisition and maintenance of these resources.

David Gaba' calls simulation a "technique" instead of a technology, denoting that a simulator is not required to carry out simulation techniques, because due to the high cost of these, it is an acquisition limitation. For this reason, institutions and areas such as orthopedics, which understand the need to implement the simulation in their curriculum program design their own simulators, as is the case of arthroscopy simulators and virtual reality programs; however, they must be validated to demonstrate that their design and applicability recreate situations similar to the real ones and that the appropriate process of meaningful learning takes place. ${ }^{13-19}$ Another use of clinical simulation within the orthopedic area is to classify the level of competence of different procedures performed by physicians through performance metrics that precisely define the performance threshold, opening the possibility of using the simulation to evaluate or certifying the level of competence. ${ }^{20,21}$

These are lots of simulation approaches in orthopedics; although it is known that orthopedic education in the postgraduate area has great relevance, within the area of undergraduate general medical training is limited, and the evidence found regarding competencies in orthopedics, existing reports show that they lack the skills needed to diagnose, treat or to refer to the specialist. ${ }^{22}$

It is necessary to implement the use of simulation in the continuous training of all levels of health personnel, both in clinical and surgical skills, technical (surgeries, sutures, exploration) and non-technical (leadership, effective communication, teamwork), which is reflected in an increase in quality of care and patient safety. ${ }^{23}$

\section{Conclusion}

Orthopedics as well as other disciplines have found an ally in simulation, for the training of students in health care areas, where they can acquire skills in a safe environment and without harming the 
patients they attend, reducing the ethical gap that involves practicing in a living being.

Most studies in orthopedic simulation focus on surgical and technical skills, where the conclusions usually coincide in that they require more studies that support the effectiveness of these techniques for professional training. However, the evidence of the application of simulation in the development of non-technical skills, such as leadership, effective communication, decision making, teamwork, should not lose relevance as an objective of the health professional profile, both in undergraduate and postgraduate; so the authors of this document recommend investing and developing studies that focus on this field.

\section{Conflicts of interest}

There is no conflict of interest in composing this manuscript.

\section{References}

1. Gaba D. The future vision of simulation in health care. Qual Saf Health Care. 2004;13(Suppl 1):i2-i10.

2. Dunn J, Belmont P, Lanzi J, et al. Arthroscopic Shoulder Surgical Simulation Training Curriculum: Transfer Reliability and Maintenance of Skill over Time. J Surg Educ. 2015;72(6):1118-1123.

3. Escoto A, Trejos A, Naish M, et al. Force sensing-based simulator for arthroscopic skills assessment in orthopaedic knee surgery. Stud Health Technol Inform. 2012;173:129-135.

4. Frank R, Erickson B, Frank J, et al. Utility of modern arthroscopic simulator training models. Arthroscopy. 2014;30(1):121-133.

5. Gandhi M, Anderton M, Funk L. Arthroscopic Skills Acquisition Tools: An Online Simulator for Arthroscopy Training. Arthroscopy. 2015;31(9):1671-1679.

6. Monje F, Hernandez C, Moyano Cuevas J, et al. Validation of a simulator for temporomandibular joint arthroscopy. Int J Oral Maxillofac Sur. 2016;45(7):836-841.

7. Amer K, Mur T, Amer K, et al. A Mobile-Based Surgical Simulation Application: A Comparative Analysis of Efficacy Using a Carpal Tunnel Release Module. J Hand Surg Am. 2017;42(5):389.e1-389.e9.

8. Aïm F, Lonjon G, Hannouche D, et al. Effectiveness of virtual reality training in orthopaedic surgery. Arthroscopy. 2016;32(1):224-232.

9. Bunogerane GJ, Taylor K, Lin Y, et al. Using Touch Surgery to Improve Surgical Education in Low- and Middle-Income Settings: A Randomized Control Trial. J Surg Educ. 2017;75(1):231-237.
10. Gottschalk M, Yoon S, Park D, et al. Surgical training using three-dimensional simulation in placement of cervical lateral mass screws: A blinded randomized control trial. Spine J. 2015;15(1):168-175.

11. Sugand K, Mawkin M, Gupte C. Validating Touch SurgeryTM: A cognitive task simulation and rehearsal app for intramedullary femoral nailing. Injury. 2015;46(11):2212-2216.

12. Vaughan N, Dubey V, Wainwright $\mathrm{T}$, et al. A review of virtual reality based training simulators for orthopaedic surgery. Med Eng Phys. 2016;38(2):59-71.

13. Bouaicha, S, Jentzsch T, Scheurer F, et al. Validation of an Arthroscopic Training Device. Arthroscopy. 2017;33(3):651-658.

14. Cannon W, Nicandri G, Reinig K, et al. Evaluation of skill level between trainees and community orthopaedic surgeons using a virtual reality arthroscopic knee simulator. J Bone Joint Surg Am. 2014;96(7):e57.

15. Khanduja V, Lawrence J, Audenaert E. Testing the Construct Validity of a Virtual Reality Hip Arthroscopy Simulator. Arthroscopy. 2017;33(3):566-571.

16. Morgan M, Aydin A, Salih A, et al. Current Status of Simulation-based Training Tools in Orthopedic Surgery: A Systematic Review. J Surg Educ. 2017;74(4):698-716.

17. Rahm S, Germann M, Hingsammer A, et al. Validation of a virtual reality-based simulator for shoulder arthroscopy. Knee Surg Sports Traumatol Arthrosc. 2016;25(5):1730-1737.

18. Tuijthof G, Rees J. Simulator evaluation. Effective Training of Arthroscopic Skills. 2015.

19. Vaughan N, Dubey V, Wainwright T, et al. Can virtual-reality simulators assess experience and skill level of orthopaedic surgeons?. Science and Information Conference. 2015.

20. Rahm S, Wieser K, Wicki I, et al. Performance of medical students on a virtual reality simulator for knee arthroscopy: An analysis of learning curves and predictors of performance. BMC Surg. 2016;16(1).

21. Lubowitz J, Provencher M, Brand J, et al. Expert Surgeons Can Be Distinguished from Trainees, and Surgical Proficiency Can Be Defined, Using Validated Metrics and Shoulder Models. Arthroscopy. 2015;31(9):1635-1636.

22. Olvera H, Ortiz A, Rubio M, et al. Evaluación de competencias clínicas para el diagnóstico de displasia del desarrollo de cadera con un simulador de bajo costo. Revista Mexicana de Ortopedia Pediátrica. 2016;18(2):67-71.

23. Hernandez L, Barona A, Durán, et al. La seguridad del paciente y la simulación clínica. Revista de la Facultad de Medicina. 2017;60(2):11-18. 